\title{
Mudança e aprendizagem organizacional, com criatividade e inovação
}

\section{Changing and organizational learning, with creativity and innovation}

\author{
Leocir Dal Pai ${ }^{1}$ \\ Agamêmnom Rocha Souza ${ }^{2}$ \\ Debora Cristina Lopes Martins ${ }^{3}$
}

Artigo
Original

Original

Paper

\section{Palavras-chave:}

Mudança

Crescimento

Aprendizagem

Organizacional

Organização que

aprende

Estímulo

Criatividade

Inovação

\section{Resumo:}

Inseridas em um mercado altamente competitivo, empresas transnacionais e regionais buscam adaptar-se às mudanças como condição de sobrevivência. Se antes as empresas mudavam por iniciativa dos gestores na busca do crescimento, hoje, mudam, principalmente, para garantir sua permanência no mercado. Organizações que aprendem com seus erros e com os erros de outras organizações e utilizam-se sinergicamente do conhecimento individual de seus empregados, são mais capazes de antecipar-se aos problemas e monitorar as variáveis incontroláveis que afetam negativamente seu negócio. Por meio da aprendizagem organizacional, as empresas tornam-se bem sucedidas, pois são capazes de promover o estímulo, a criatividade e a inovação.
Recebido em $10 / 2011$

Aprovado em 03/2012

\section{Abstract}

Regional and multinational companies, inserted in an extremely competitive market, seek to adapt to changes as a state of survival. If previously the companies changed by initiative of managers in pursuit of growth, currently they change, largely, to ensure their stability in the market. Organizations that learn from their mistakes, with the mistakes of other organizations and, synergistically, make use of individual knowledge of their employees are able to anticipate the problems and monitor the uncontrollable variables that affect negatively their business. By means of organizational learning, companies become successful for the reason that they are able to encourage stimulation, creativity and innovation
Key words:

\section{Changing}

Growth

Organizational

Learning

Organization That

Learns

Stimulation

Creativity

innovation.

\footnotetext{
1.Administrador, mestre em administração, doutorando em administração pela UNR (Universidad Nacional de Rosário Argentina), Delegado do CRA em Niterói, Coordenador do Curso de Administração da Universidade Salgado de Oliveira/ Niterói-RJ, Avaliador do MEC/INEP para Cursos de Administração e consultor empresarial.

2.Professor do UniFOA - Centro Universitário de Volta Redonda, Conselheiro-representante do Corpo Docente dos Cursos da Área de Ciências Humanas/ Sociais aplicadas-CONSUN, Coordenador do Curso de Ciências Contábeis, Membro do Conselho Fiscal - VR Empresa Júnior e Docente do Curso de Administração.
} 


\section{Introdução}

Mudança pode ser conceituada, segundo Chiavenato, (2008, p. 12) como "a passagem de um estado para outro. É a transição de uma situação para outra diferente. Mudança representa sempre transformação, alteração, modificação, perturbação, interrupção, fratura ou ruptura". Também podemos conceituar mudança, de acordo com Fernandéz Gatti (2007), como a capacidade que têm as organizações de se adaptarem às transformações exigidas por forças endógenas e exógenas, mediante a aprendizagem e que se traduz em nova estrutura ou novo comportamento para a organização.

Heráclito afirma que a única certeza que podemos ter é de que a mudança ocorre permanentemente. Com bom humor, Chiavenato (idem, 5), acrescenta àquela certeza, "a morte e os impostos". Hoje, não mudar, no mínimo, significa perda de mercado pela não incorporação de novas tecnologias, tendências e competitividade.

A maneira como as pessoas e organizações têm se adaptado às mudanças ao longo da linha do tempo tem se diferenciado principalmente na velocidade em que ocorrem, porém, na essência, sempre foram realizadas com o mesmo objetivo: a sobrevivência.

A inércia que caracterizava a transformação organizacional no passado se devia em razão de que esta ocorria basicamente em função de sua expansão e não por imposição do mercado. Mudava-se somente por que se desejava crescer e os sistemas ou estruturas planejadas já não eram adequadas. Hoje, mudamos para permanecermos no mesmo lugar, ou seja, somos obrigados a mudar mesmo que não tenhamos ambições de crescimento.

$\mathrm{O}$ conceito de mudança não é algo recente, nem exclusivo das organizações. Se observarmos a natureza, esta tem operado constantes mudanças ao longo do tempo. A transformação do universo do estado de caos para a organização concretiza uma grande mudança. Podemos também citar as mudanças ocorridas no mundo empresarial e bem referenciadas por Toffler (1989) que as chama de "ondas", a primeira ligada à agricultura; a segunda, ligada à industrialização; e a terceira, às comunicações ou informações. Outros autores- dentre os quais destaca-se Schumpeter (1999)- também se referem às mudanças, fazendo uma distribuição aleatória de intervalos de tempo para classificá-las.

A globalização da economia tem exigido das empresas, tanto das transnacionais, como das que operam regionalmente, flexibilidade e uma enorme capacidade de adaptação à mudança como condição de sobrevivência. A mudança é para a gestão um momento muito crítico. Podemos afirmar que a função básica do administrador é, hoje, gerir a mudança. Maquiavel (1977, p.34) afirma “...que coisa mais dificil não há, nem de êxito mais duvidoso, nem mais perigosa, do que o estabelecimento de leis novas", demonstrando a sensibilidade que deve ter o gestor no momento da mudança, da quebra de um paradigma e do estabelecimento de uma nova ordem das coisas.

Dentre as teorias utilizadas para abordar a mudança, consideramos a "Teoria da Evolução" de Charles Darwin (1883) como muito importante, pois, é aplicada indistintamente aos seres vivos e organizações e pode ser resumida em uma única frase: "não é $o$ mais forte, nem o mais inteligente que sobrevive, mas o que melhor se adapta às mudanças". A condução equivocada do processo de mudança, sem envolver a cultura e a aprendizagem organizacional, faz com que empresas sólidas percam competitividade, mercado e, num curto espaço de tempo, deixam de existir. As organizações necessitam incorporar velocidade na mudança, antecipando-se aos problemas, procurando, com uma visão pró-ativa, ganhar tempo para exercitarem o gerenciamento das crises, procurando evitá-las, minimizando seus danos ou neutralizando seus efeitos.

\section{Tipos De Mudança}

Vários são os autores (Robbins, Kanter, Beer \& Nohris, Blake \& Mouton) que tratam dos tipos de mudança. Blake \& Mouton (in Chiavenato, 1999, 326) apresentam um modelo que nos pareceu mais amplo, utilizando-se de três tipos de estratégias utilizadas pelas organizações com o objetivo de alcançar seu desenvolvimento: 
- Mudança evolucionária: é uma mudança lenta, incremental e de controle. Tem como objetivo manter o estado atual desejado para a organização, reforçando e repetindo soluções passadas;

- Mudança revolucionária: é a que destrói os arranjos existentes. É rápida, intensa, brutal, transgressiva e rejeita antigas expectativas, introduzindo uma nova ordem para a empresa;

- Desenvolvimento sistemático: os responsáveis pela mudança traçam um modelo considerando o que é a organização e o que deveria ser. A principal vantagem desse modelo é que, através do planejamento e da aprendizagem organizacional, a mudança acontece com menor resistência, causando menos estresse pelo envolvimento dos diversos atores e pela transparência do processo.

\section{Aprendizagem Organizacional}

Entre os autores consultados, não há um consenso sobre o conceito de aprendizagem organizacional. Cada autor a define de uma maneira, variando o conceito em função da análise considerada em nível individual, grupal ou organizacional; e, em função da natureza do processo, como estrutural, cultural, cognitivo ou comportamental.

O conceito que nos pareceu mais amplo, abarcando todos os aspectos, foi o de Malanovicz (2008), para quem aprendizagem organizacional é:

\footnotetext{
"o processo de apropriação de novos conhecimentos nos níveis individual, grupal ou organizacional, envolvendo todas as formas de aprendizagem - formais e informais - no contexto organizacional, alicerçando em uma dinâmica de reflexão e ação sobre as situações-problema e voltado para o desenvolvimento de competências gerenciais".
}

Para Fiol \& Lyles (1985) aprendizagem organizacional é o processo que permite a melhoria e o desenvolvimento das ações or- ganizacionais, através da aquisição de novos conhecimentos e de melhores compreensões, bem como sua correta utilização pela empresa.

Shrivastava (1981, p.15) aborda o conceito de aprendizagem organizacional sob o aspecto cognitivo e com foco organizacional, referindo-se a ela

\begin{abstract}
"como um processo em que a base de conhecimento organizacional é construída e desenvolvida". Já para Kart Weick (in Fernandéz Gatti, 2007) "é o processo pelo qual uma organização (como grupo e cada um de seus membros pessoalmente) descore, divide, avalia e cria seus pressupostos culturais mais profundos com o objetivo de imaginar, desenhar e aprender um futuro comum".
\end{abstract}

Segundo Duncan e Weiss (in Leonor Cardoso 2000), a análise da "aprendizagem organizacional reporta-se e reporta-nos, a um nível organizacional, ao nível de sistema, e não a um nível individual e deve entender-se enquanto processo através do qual se desenvolve o conhecimento sobre o resultado da organização com o seu meio ambiente". Bastos \& outros (2002) por sua vez, alega que uma posição crítica nega para as empresas o poder de aprender, que nada mais é do que o uso de uma metáfora, atribuindo propriedades humanas à organização, já que esta não tem o poder de aprender e que por trás dessa discussão está o voluntarismo e o determinismo, que questiona "até que ponto os indivíduos são sujeitos autônomos e capazes de construir uma realidade e até que ponto são produtos dessa realidade e dessa estrutura”. Para o mesmo autor, os que defendem a aprendizagem em nível individual afirmam que o indivíduo age e aprende na organização, pois é o indivíduo que aprende, cria estruturas, estabelece os fluxos de informações, etc. Já os que defendem a aprendizagem como organizacional, supraindivíduos- alegam que a aprendizagem organizacional é sinérgica, ou seja, é maior que a soma das aprendizagens de cada indivíduo e que a organização pode aprender independentemente da vontade de uma única pessoa.

Importante é a contribuição de Weick (in Bastos \& outros, 2002) que afirma que " $a$ 
aprendizagem individual ocorre quando as pessoas dão diferentes respostas a um mesmo estímulo, enquanto que a aprendizagem organizacional ocorre quando um grupo de pessoas dá a mesma resposta a diferentes estímulos".

Concluindo e usando como referencia as ideias Probst e Büchel (in Bastos \& outros, id.), haverá aprendizagem organizacional quando:

- a mudança ocorrer em nível de grupo ou sistema

- se constatar mudança nos conhecimentos e valores coletivos, e

- observadas mudanças nos padrões comportamentais e normativos coletivamente partilhados.

Dessas ideias, concluí-se que a aprendizagem individual (Kim, in Bastos \& outros, id.) ocorre a partir da experiência, reflexão e observação e que esta só se torna organizacional a partir do compartilhamento e da disseminação, criando uma unidade de entendimento com significados mais ou menos comuns sobre determinado contexto.

\section{Organizações Que Aprendem}

A expressão "organizações que aprendem" tem surgido conceitualmente para amparar um conjunto de ideias que visam tornar as organizações mais ágeis e receptivas no atendimento às necessidades dos consumidores (Kiechel, in Bastos \& outros, 2002). Fernandéz Gatti (2007) acolhe o conceito "como o processo mediante o qual a organização aprende”, provocando a mudança no comportamento organizacional "ou na mudança da teoria de ação da organização" ou, na base de conhecimento da organização, incrementando sua capacidade de ação. Para Senge (1990) é aquela em que os seus colaboradores, em conjunto, permanentemente "expandem as suas capacidades no sentido de criar resultados desejados" para a organização.
Para Fernandéz Gatti (2007), organização que aprende

“.. é aquela que está em constante aprendizagem, que gera, incorpora, utiliza, divide e distribui conhecimento, detecta suas incapacidades ou limitações para aprender e as soluciona, tira proveito de seus erros, aprende com as experiências e práticas próprias e de outras empresas, está disposta a dar respostas às mudanças e necessidades da sociedade, é comprometida com a melhora contínua e é capaz de se autoavaliar e de ser avaliada externamente".

Para Presser (1999) as melhores organizações são as que conseguem despertar em seus empregados a vontade de aprender e as mais competitivas são as que destinam recursos para o conhecimento, fonte da inovação, competitividade e sobrevivência.

\section{Níveis De Aprendizagem}

Agirys e Schön (in Fernandéz Gatti, 2007) distinguem níveis de aprendizagem em ciclos. A aprendizagem de "ciclo simples" é a mais comum e ocorre quando a organização percebe alterações ambientais detectando erros, os quais são corrigidos para manter os controles, mas sem alterar substancialmente seu curso, conservando a teoria organizacional e o clima reinante. A aprendizagem de "ciclo duplo" é considerada mais elevada porque encoraja o debate, a inovação, implica mudança radical na teoria organizacional em uso e surge da necessidade de resolver "incompatibilidades normativas mediante o estabelecimento de novas prioridades e ponderações de normas" (id, id.).

Há também um terceiro nível de aprendizagem identificado com a capacidade de “aprender a aprender”, que segundo Argyris e Schön ( in Fernandéz Gatti, id.) tem a ver com a capacidade adquirida pela organização de questionar-se sobre sua capacidade de aprendizagem e, quando atingido esse nível, a empresa é capaz de aumentar seu potencial continuadamente. 
Outras classificações são vistas na mesma obra, diferenciando-as em aprendizagem adaptativa e generativa (McGill, Slocum e Lei, in id. id.). "A aprendizagem "adaptativa" realiza melhoras, porém, limitadas ao marco de ação estabelecido", da mesma maneira que a aprendizagem de "ciclo simples". A "generativa" muda radicalmente o marco de ação global, da mesma forma que acontece na de "ciclo duplo" de Argyris e Schön. Fiol y Lyles (id, id.) classificam a aprendizagem em baixo nível" e "alto nível", respectivamente equivalente a de "ciclo simples" e de "ciclo duplo".

Não seria demasiado aduzir que as organizações mais bem-sucedidas estimulam a criatividade e a inovação, tornando-as verdadeiros constructos de suas próprias culturas, podendo ser apontadas, dentre outras, algumas possuidoras de fortes culturas inovadoras: Totvs (sucessora da Microssiga), HewlettPachard, Intel, Procter \& Gamble, Texas Instruments e 3M.

As organizações inovadoras tendem a ter culturas semelhantes que estimulam a experimentação. Nesse complexo universo, as culturas inovadoras normalmente têm as seis características seguintes (LUSSIER, REIS e FERREIRA, 2010, p. 220-1):

- "Encorajar o risco. As culturas inovadoras estimulam os funcionários a serem criativos, sem medo de punição se falharem. Erros e falhas são considerados experiências de aprendizado. Por exemplo, cerca de $60 \%$ das inovações na $3 \mathrm{M}$ não têm sucesso no mercado.

- Intraempreendedorismo. A ação intraempreendedora estimula o desenvolvimento de negócios que possam se tornar unidades separadas de negócios. Intraempreendedorismo é normalmente visto em três funções nas organizações: $\mathrm{O}$ inventor é aquele que aparece com uma ideia criativa. Entretanto, os investimentos não têm habilidade para transformar a ideia em inovação. O campeão é o responsável pela transformação da ideia em inovação. Este, geralmente um gerente de nível médio, acredita na ideia e a promove, procurando um patrocinador na organização que forneça os recursos necessários para a inovação. O patrocinador, um gerente de nível alto, apoia a inovação, fornecendo os recursos e a estrutura necessários à inovação. $\mathrm{Na}$ Texas Instruments somente as ideias criativas com um inventor, um campeão e um patrocinador são formalmente transformadas em produção ou serviços.

- Sistemas abertos. Os membros da organização constantemente examinam o ambiente para ter ideias criativas. O benchmarking é geralmente praticado por essas organizações.

- Foco nos fins, e não nos meios. As culturas inovadoras informam aos funcionários os objetivos (fins), mas os funcionários decidem sobre os meios de consegui-los.

- Aceitação de ideias ambíguas e impraticáveis. A exigência de ideias claras e possíveis de ser colocadas em prática emperra a criatividade. As culturas inovadoras estimulam os funcionários a trabalhar em ideias criativas, mesmo quando os gestores não têm uma ideia clara do que eles estão fazendo.

- Tolerância do conflito. "As culturas inovadoras estimulam a diversidade de opiniões como um modo de dar livre trânsito a ideias criativas".

\section{Conclusões}

Da bibliografia referenciada, do contexto atual e da vivência profissional, com relação à mudança, aprendizagem organizacional e as organizações que aprendem, chegam-se as seguintes conclusões:

As organizações que não estão aptas à mudança, conforme preconiza a teoria da evolução, sejam grandes ou pequenas, vão fatalmente desaparecer, e isso acontece todos os dias, no Brasil, na Argentina, nos Estados Unidos ou em qualquer país do mundo. A adaptação poderá ocorrer basicamente de duas maneiras: a organização pode atuar como vítima da mudança e desaparecer; ter uma atitude reativa e cambaleante, ressurgir das cinzas como Fênix; 
ou ser a organização agente de mudança, provocando oportunamente as rupturas, as crises, se antecipando, tendo uma atitude pró-ativa determinando a mudança e o ritmo em que esta se processa. Para que isso aconteça, é necessário que a empresa seja bem provida de informações e estas traduzidas em conhecimento organizacional que faculte o processo decisório.

A mudança é a uma prova pela qual toda organização tem que passar. Surge da turbulência, da instabilidade e do conflito. Não gostamos de mudança, gostamos de rotinas e de estabilidade. Maquiavel (1977, 34) mais uma vez nos ilustra isso, dizendo que teremos como nossos aguerridos inimigos todos aqueles que possam ser prejudicados pela mudança e como tíbios defensores aqueles para quem a mudança possa trazer algum benefício. Isso mostra o quanto é solitário o gestor e quantas vezes é isolado o ato de decidir. Deve o gestor saber que a mudança não agrada ao cidadão comum desmotivado. Essa motivação vai ocorrer através da aprendizagem organizacional. O gerenciamento da mudança permite um clima de maior estabilidade. As mudanças organizacionais deverão ocorrer sistematicamente o que diminui o nível de incerteza e o estresse na organização. Devem ocorrer através do processo de aprendizagem organizacional, que tem como papel preparar os indivíduos e a organização na busca de novas formas e arranjos para sobreviver. A aprendizagem é então um processo dinâmico realizando a interação entre a aprendizagem organizacional e individual, que não se excluem e sim se complementam mutuamente na organização que aprende.

A empresa que aprende utiliza-se sinergicamente do conhecimento individual de todos os seus empregados, questiona-se, aprende com seus erros e com os erros de outras organizações.

Certo é que as organizações mais bem-sucedidas promovem o estimulo, a criatividade e a inovação, tornando-os um autêntico tripé de suas próprias culturas.

Para finalizar, cabe dizer que a empresa que aprende evidencia mudança como grupo, muda valores e comportamentos. Mas isso não acontece naturalmente, nem é responsabilidade voluntariosa dos empregados, tem um preço e a organização tem que investir nisso. 


\section{Referências}

1. ARGYRIS, C. \& SCHÖN, D.A. Organizational Learning: a theory of action perspective. Reading, MA: Addison-Wesley, 1978

2. BASTOS A.V.B.; GONDIM S.M.G; \& OUTROS. Aprendizagem organizacional versus organizações que aprendem: características e desafios que cercam essas duas abordagens de pesquisa. PORAD/ UFPE:AMPAD: Recife, 2002.

3. CARDOSO, Leonor. Aprendizagem organizacional. Psycologica. Universidade de Coimbra: Coimbra, Portugal, 2000.

4. CHIAVENATO, Idalberto. Teoria geral da administração. S. Paulo: Campus, 1999

5. CHIAVENATO, Idalberto. Os novos paradigmas. S. Paulo: Manole, 2008

6. DARWIN, Charles. Voyage D'um Naturaliste Autor Du monde. Paris, 1883.

7. FERNANDÉZ GATTI, María Andrea. Empresas de Rosario: un modelo de cambio basado en el aprendizaje. Tesis doctoral de Doctorado en administración. Facultad de Ciencias Económicas y Estadística. UNR: Rosario, Argentina, 2007.
8. FIOL \& LELIS. Organizational learning. Academy of Management Review, vol. $10 \mathrm{n}^{\mathrm{o}} 4$, p. 803-813.

9. LUSSIER, Robert N., REIS, Ana Carla Fonseca e FERREIRA, Ademir Antônio. Fundamentos de administração: Tradução e adaptação da $4^{\mathrm{a}}$ edição norte-americana; [tradução Guilherme Rocha Basílio e Marta Reyes Gil Passos]. São Paulo: Cengage Learning, 2010.

10. MACHIAVELLI, Niccoló. O príncipe. Hemus: S. Paulo, 1977.

11. MALANOVICZ, Aline. Aprendizagem organizacional. Porto Alegre, 2008. Disponível em htpp://recantodasletras. uol.com.br/ensaios/946634

12. PRESSER, Nadi H. Como ocorre o processo de aprendizagem organizacional na formação de estratégias: o caso da Intelbras. Congresso Brasileiro de administração: Florianópolis - SC, 2000.

13. SENGE, P.M. A Quinta disciplina. Arte, teoria e prática da organização da aprendizagem. Nova Cultural: S. Paulo, 1990.

14. SHRIVASTAVA, P. A tipology of organizational learning systems of management studies. Vol. 20, $\mathrm{n}^{\mathrm{o}} 1, \mathrm{p}$ 7-28, 1981.

\section{Endereço para Correspondência:}

Agamêmnom Rocha Souza agamemnom.souza@foa.org.br

Centro Universitário de Volta Redonda - UniFOA Campus Olezio Galotti

Av. Paulo Erlei Alves Abrantes, nº 1325

Três Poços - Volta Redonda - RJ

CEP: 27240-000 